or shipborne interrogator. And in 'Gee' and 'Loran' and related systems it will depend on a measurement in the craft of the time-difference of arrival of primary pulses from synchronized ground stations in accurately surveyed positions.

In a well-ordered world-which includes, but goes beyond, a world at peace-primary radar would have no place in aviation save as an airborne means of avoiding dangerous high ground and dangerous clouds and as a 'last resort' ground system for locating aircraft whose responders had failed, as they may on occasion do even in a well-ordered world. In the shipping world it would have a corresponding role, save that all ground is then dangerous high ground and the iceberg is the equivalent of dangerous cloud. In land transport primary radar should have no place at all; but primary radar on the ground will help the meteorologist in his still difficult task of forecasting. The world has still some way to go before even an optimist will regard it as well-ordered, and so ships will sail and aircraft fly with primary radar performing other duties which will ultimately be better confided to secondary radar.

The aim of the radar aids to civil aviation which were discussed at the recent Third Commonwealth and Empire Conference on Radio for Civil Aviation. (C.E.R.C.A.) in London is to give from a generous provision of ground installations and the minimum of equipment in the aircraft, sufficient information (without the intervention of communications from ground controllers) for the pilot to know at every moment where he is, how to fly to his destination by the shortest or safest route, and how to land safely whatever the visibility. These provisions will be supplemented by radar aids which will keep the air traffic controller fully informed of the traffic pattern around his airport and on his designated routes. It will not be done cheaply, but independence of the weather has never been cheaply bought.

The simpler problems of marine transport find simpler radar solutions, and the sea and air transport without which our great Commonwealth and Empire cannot hold together in its service to civilization need radar services with an urgency second only to that which produced radar services in war.

Of railroad radar no one will at this date speak with equal confidence. But it is surely reasonable to believe that the simple elements of secondary radar in cab, cabin and caboose will at last banish the primitive detonator from this fog-girt isle! Romance cannot wholly dispense with radar in its noble task of bringing up the eight-fifteen-especially in the not infrequent conditions in which it is not romance alone that is 'all unseen'.

\title{
SCIENCE IN THE U.S.S.R. ${ }^{*}$
}

\section{ASTRONOMY AND TERRESTRIAL MAGNETISM \\ BY SIR HAROLD SPENCER JONES, F.R.S. Astronomer Royal}

$\mathrm{R}^{\mathrm{t}}$ USSIA has played an important part in the development of astronomy since the foundation of the Pulkova Observatory by Czar Nicholas in 1839. Under the direction of F. G. W. Struve, this observatory was built regardless of expense. It has made notable contributions to fundamental astronomy, its instrumental equipment for such observations being more varied and complete than that of any other observatory. The Pulkova observations have always been characterized by their great accuracy. At the beginning of the present century, the work was expanded to include astrometry and astrophysics. Its great refractor, of 30 -inches aperture and 45-feet focal length, was one of the finest in the world. In 1908 an astrophysical observatory was established at Simeis in the Crimea. There were, at the time I visited Russia in 1914, several other observatories, but for the most part their equipment was modest and their staffs were small. Since the Revolution a great expansion in astronomical work has occurred. Additional instrumental equipment has been installed, including the 40-inch reflector at Simeis : new observatories have been constructed in Abastumani (Georgia), Stalinabad (Tajikistan), Yerevan (Armenia), Poltava (Ukraine) and Alma Ata (Kazakhstan), the last of these during the war years. Astronomical institutes have been established in Moscow and Leningrad, for computational and theoretical work in the fields both of astrophysics and of celestial mechanics. The total staffs have been increased about ten-fold.
In the pre-Revolution days, each observatory worked alone, and its resources were generally insufficient to enable large programmes of observation to be undertaken. In the Soviet years an Astronomical Council has been constituted by the Academy of Sciences which co-ordinates the work of the various observatories, including both those which come directly under the Academy and those which are attached to universities. Thus, it has been possible, by pooling of effort, to undertake fields of work which are beyond the scope of any single observatory and also to avoid unnecessary duplication. For example, observations of selected minor planets and of the positions of some 16,000 red giant stars have been undertaken at several observatories for the improvement of the fundamental system of star places. Special attention has been given to solar phenomena and their terrestrial relationships. The paths of totality of the total solar eclipses of 1927 , 1936, 1941 and 1945 have crossed Soviet territory and extensive programmes of observation were planned. For the last three of these eclipses some fifteen to twenty expeditions were organized and were distributed along the line of totality-valuable results being obtained.

The time service has been extended, and its accuracy considerably improved. A Nautical Almanac is published to meet the needs of navigators and surveyors as well as astronomers. The computations for its production are made at the Astronomical Institution in Leningrad.

Soviet astronomers have made important contributions to the theory of the structure of comet tails and heads, to the problems of the variation of latitude, to the study of the atmospheres of stars (including the discovery of heavy isotopes of carbon), to the problems of novæ, and to cosmogony.

Astronomy in the U.S.S.R. has suffered a serious setback through the destruction of, or damage to, 
various observatories. The Pulkova Observatory was in the front line for two and a half years in the fighting around Leningrad and has been completely destroyed by German shelling and bombing, though some of the instruments were saved. Most of its valuable astronomical library, probably the most complete in the world, has been lost; some of its treasures, including the manuscripts of Kepler, were fortunately saved. Its destruction was no doubt inevitable in the circumstances. But it was otherwise in the case of the Simeis Observatory, for no fighting took place in its vicinity. The Germans removed the telescopes (which have since been found in Potsdam, but in a state unfit for use), most of the library and most of the astronomical negatives; they then deliberately set fire to and destroyed the Observatory. The Observatories at Odessa, Kiev, Nikolaiev, Kharkov and Poltava were all badly damaged. Many of the observational records have been removed or destroyed, so that some of the co-operative programmes of observation, on which much work had been done, will have to be commenced anew. Many of the astronomers and some of their instruments were evacuated far into the interior. Some of the Pulkova astronomers were moved from Leningrad by aeroplane during the siege. Throughout the War a considerable amount of research in astronomy was continued in spite of the difficulties of the conditions.

The reconstruction of some of the damaged observatories has already been commenced. Plans have been prepared for the rebuilding of the Pulkova Observatory according to its original plan; the telescopes which were saved will be replaced in their original positions. But new additional instruments will be installed. Plans are under consideration for the establishment of a large astrophysical observatory in the Crimea, provided with powerful reflecting telescopes and with instruments of modern types; there may be also a subsidiary station somewhere in the southern hemisphere.

Mention may be made of the invention by Dr. Maksutov during the War of the new system of meniscus lens telescopes which, because only spherical surfaces are employed, are simple to manufacture. These telescopes are powerful and extremely com. pact. The largest meniscus telescope as yet constructed is of nine inches aperture; but telescopes of this type and of greater aperture are to be constructed for astronomical observation.

It is certain that the U.S.S.R. is destined to play a prominent part in the development of astronomy in the post-war years.

The Institute of Terrestrial Magnetism, established in Leningrad in 1940, embraces a wide field of work. It eomprises sections for land magnetic surveys, sea magnetic surveys, magnetic observatories, magnetic cartography, ionospheric and cosmic ray observations, and theoretical investigations. Nineteen permanent magnetic observatories, including some high-latitude stations, were in operation when the War started. Six of these at Yanov, Stepanovka, Novgorod, Amvrossievka, Nizhnedevitsk and Pavlovsk were occupied by the Germans in 1941-42: same of the staffs were evacuated and some were made prisoners. When the Germans retreated they burned or blew up the observatory buildings in Pavlovsk, Novgorod and Nizhnedevitsk. Obseryational records and instruments were removed or destroyed. The magnetograms of the Second Polar Year stations have disappeared. Profs. Weinberg and
Trubyatchinsky died of famine during the siege of Leningrad. Magnetic survey work has been continued during the War, and some expeditions were sent to the north of Siberia. Observations are made at regular intervals at a number of repeat stations for the determinations of secular changes. Magnetic anomalies associated with possibly useful mineral deposits have been studied. Solar, magnetic and ionospheric data are collected and summaries are published in ten-day cosmic bulletins.

The Institute is to be moved to a site near Moscow, where special buildings are to be erected, and the magretic observatories destroyed by the Germans are to be re-established. Theoretical investigations in terrestrial magnetism and allied subjects are also carried out at the Institute for Theoretical Physics in Moscow, where Prof. Frenkel has recently developed new theories of atmospheric electricity and of the earth's magnetism. Among other work undertaken at this Institute are theoretical investigations of the scattering of light in the earth's atmosphere and of atmospheric transparency, and the study of the light of the night sky.

\section{THEORETICAL PHYSICS \\ By PROF. M. BORN, F.R.S. University of Edinburgh}

$I^{N}$ $\mathrm{N}$ the original group of British delegates to the Moscow conference, theoretical physics was well represented (Darwin, Dirac, Mott and myself); but I was the only one allowed by the Government to proceed. The following account is therefore based only on the observations of one pair of eyes and ears, which had to absorb a multitude of impressions vastly more interesting and important than even the most fascinating scientific things : a new and strange type of civilization in its various activities, social, economic, military, scientific, artistic, etc.

Theoretical physics can scarcely be separated from physics in general, on which Andrade has reported in a previous number of Nature (August 25, p. 223). I shall add a few remarks to his excellent account, but speak mainly about the more abstract branches of my subject. As the Soviet State is based on a definite philosophical system, the question arises whether this fact has any influence on the development of fundamental ideas in physics. I have found scarcely any traces of such an influence, and certainly no restrictions of research. The Russian physicist interprets the facts of observation in the same spirit of intellectual freedom as his Western colleague, and indulges in any speculation on cosmology, relativity or quantum theory without being censored. Nor does the question of the practical applicability play a great part, as many of the reports on other subjects have already stressed. Fundamental research is acknowledged as the basis for a sound growth of science, and a theoretical physicist is no more expected to produce results of economical importance than the roots of an apple tree to bear fruit; but if the roots are allowed to spread freely the branches carry a good crop.

The theory of relativity has a powerful representative in V. A. Fock (Moscow). A most important paper of his which appeared just before the War (February 1939) is little known in Britain. It contains the solution of the fundamental problem, also treated. by Einstein (and collaborators), whether the field 